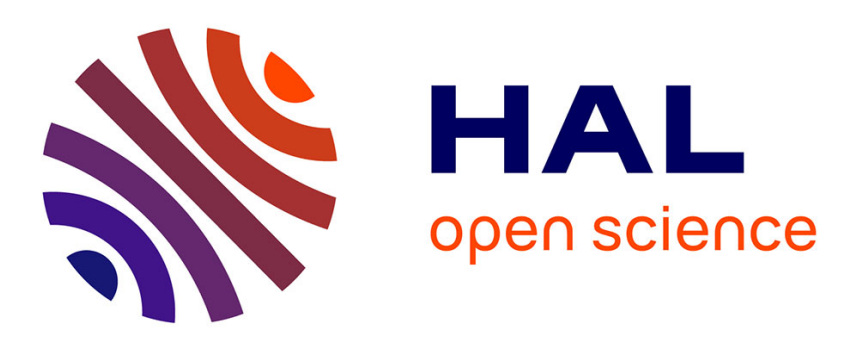

\title{
Design, manufacturing and demonstration of acoustic liners for air conditioning systems
}

\author{
E. Piot, J-Ph. Brazier, F. Simon, V. Fascio, C. Peyret, J. Ingenito
}

\section{To cite this version:}

E. Piot, J-Ph. Brazier, F. Simon, V. Fascio, C. Peyret, et al.. Design, manufacturing and demonstration of acoustic liners for air conditioning systems. 22nd AIAA/CEAS Aeroacoustics Conference, May 2016, Lyon, France. pp. 1-14. hal-01812075

\section{HAL Id: hal-01812075 https://hal.science/hal-01812075}

Submitted on 11 Jun 2018

HAL is a multi-disciplinary open access archive for the deposit and dissemination of scientific research documents, whether they are published or not. The documents may come from teaching and research institutions in France or abroad, or from public or private research centers.
L'archive ouverte pluridisciplinaire HAL, est destinée au dépôt et à la diffusion de documents scientifiques de niveau recherche, publiés ou non, émanant des établissements d'enseignement et de recherche français ou étrangers, des laboratoires publics ou privés. 


\title{
Design, manufacturing and demonstration of acoustic liners for air conditioning systems
}

\author{
E. Piot, J-Ph. Brazier ${ }^{\dagger}$ F. Simon ${ }^{\ddagger}$ \\ ONERA - The French Aerospace Lab, F-31055, Toulouse, France \\ V. Fascio $\$$ \\ ATECA, Verlhaguet, 82000 Montauban, France \\ C. Peyret \\ ONERA - The French Aerospace Lab, F-92322, Châtillon, France \\ J. Ingenito" \\ Liebherr-Aerospace Toulouse SAS, 31016, Toulouse, France
}

\begin{abstract}
Until now, acoustic liners for air conditioning systems are made of porous materials, very efficient for sound absorption in the high-frequency range. However, Liebherr Aerospace is developing an electrically driven air system composed of an air pump which generates lowand mid-frequency noise. New kinds of acoustic liners are therefore required to mitigate this noise source. The ALIAS project (Acoustic Liners for Air conditioning Systems) has been launched in the framework of Clean Sky Systems for Green Operations platform for addressing this issue. The project aimed at designing optimized locally reacting treatments for mid-frequency acoustic attenuation in air conditioning systems. SDOF and DDOF liners, which are standard solutions for acoustic treatments in turbofan engines, were adapted to the air conditioning system environment. The French Aerospace Lab (ONERA) and the SME ATECA, specialized in Advanced Materials \& Systems, combined their research and technological capabilities to propose solutions that meet the industrial requirements. This was achieved by implementing a simulation-based design process, performing dedicated laboratory experiments, manufacturing full scale prototypes and demonstrating their efficiency in the anechoic facility of Liebherr Aerospace.
\end{abstract}

\section{Nomenclature}

$\begin{array}{ll}\rho_{0} & \text { air density } \\ c_{0} & \text { air sound speed } \\ \nu & \text { air kinematic viscosity } \\ f & \text { frequency } \\ \omega & \text { angular frequency, }=2 \pi f \\ t & \text { time } \\ x & \text { axial coordinate } \\ r & \text { radial coordinate } \\ \theta & \text { azimuthal coordinate } \\ m & \text { azimuthal mode number }\end{array}$

*Research Scientist, ONERA DMAE-ITAC, estelle.piot@onera.fr

${ }^{\dagger}$ Research Scientist, ONERA DMAE-ITAC, jean-philippe.brazier@onera.fr

${ }^{\ddagger}$ Research Scientist, ONERA DMAE-ITAC, frank.simon@onera.fr

$\S$ Research Engineer, ATECA, v.fascio@ateca-fr.com

『Research Scientist, ONERA DMFN-NFLU, christophe.peyret@onera.fr

" Engineer, johanna.ingenito@liebherr.com 


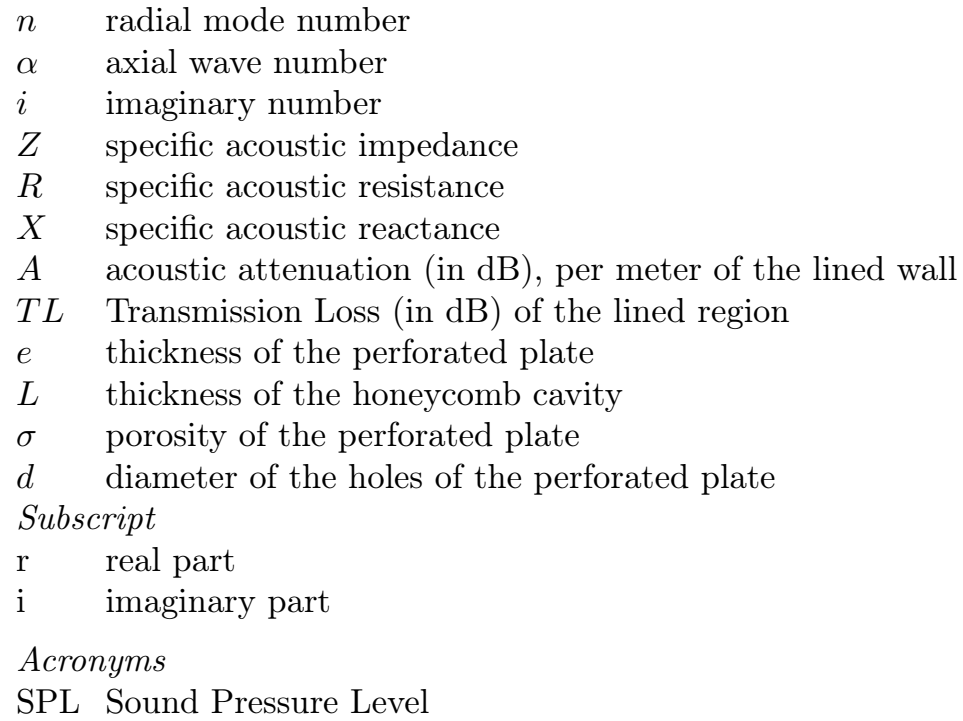

\section{Introduction}

On modern aircrafts, passengers and crew breathe a mixture of fresh and recirculated air. This combination rather than fresh only allows the regulation of temperature, pressure and humidity. The air is bled from the engines and supplied to air conditioning units. It is then ducted into the cabin, circulated and eventually drawn into the lower fuselage where it is sucked out by the pressurization outflow valve for the cycle to begin again. Besides creating a safe and comfortable environment, the aircraft air conditioning systems generate noise. The noise radiated from the aircrafts' air conditioning systems is reduced thanks to acoustic liners. These liners present a major design challenge because of the need to address a wide range of conflicting requirements. Acoustic liners must provide high levels of noise reduction over a wide range of operating conditions. They should also be light and flexible to meet strict weight and tight space restrictions.

Until now, acoustic liners for air conditioning systems are made of porous materials, very efficient for sound absorption in the high-frequency range. However, Liebherr Aerospace is developing an electrically driven air system composed of an air pump which generates low- and mid-frequency noise. Locally-reacting liners made of a multiple layers of a honeycomb core topped by a perforated facesheet are classically used in turbofan engine nacelles for mitigating fan noise. ${ }^{1,2}$ These liners are denoted as SDOF (Single Degree of Freedom) or DDOF (Double Degree of Freedom) liners depending on the number of perforate-over-honeycomb layers. Mid-frequency noise attenuation (in the range of $1-5 \mathrm{kHz}$ ) can easily be obtained by tuning the liner acoustic impedance to a target value specific to the duct environment (geometry, flow Mach number, noise source modal content). ${ }^{3}$ The impedance achieved by a SDOF or DDOF liner depends on its geometry (porosity and holes diameter of the facesheets, honeycomb depth), on the grazing flow features, and on the noise source level. ${ }^{4,5}$

During the ALIAS project, a simulation-based design process has been implemented to assess the liners concepts that were the best suited for attenuating the air pump noise in the mid-frequency range. A trade-off between acoustic efficiency, weight and cost manufacturing issues was made before selecting the liners. Two full scale prototypes were manufactured and tested in the Liebherr Aerospace anechoic facility, downstream of an air pump with realistic operating conditions. The obtained acoustic attenuation proved to be as high as expected. This paper presents all steps of the design and demonstration process that was implemented, which relied on both numerical simulations and experimental validations.

\section{Design and selection of the acoustic liners}

At the beginning of the project, Liebherr Aerospace provided some technical specifications. A range of target frequency and source noise level was given, as well as the target mean flow Mach number within the lined section and manufacturing constraints (space, weight and cost restrictions). The part of the duct 
which has to be treated is a truncated cone, whose maximum diameter is small enough so that at most three acoustic modes are cut-on at the highest studied frequency. This low number of cut-on modes make the liner design much more simple than in turbofan ducts. ${ }^{6}$

In this section, each step of the design process is detailed, until the selection of the most promising liner concepts.

\section{A. Definition of the target impedance}

First of all, numerical simulations were performed to assess a target impedance of the lined walls, for each of the third-octave frequency in the studied frequency range. As a first step, the industrial geometry was simplified into a cylindrical duct, so that mode attenuation could be computed with fast modal analysis code (MAMOUT, see $^{7}$ for instance). Each value of the acoustic field is sought under the modal form :

$$
\psi(r, x, \theta, t)=\hat{\psi}(r) \exp [i(\omega t-\alpha x-m \theta)]
$$

which yields, after linearization of the Euler equations and selection of the mean flow and lined wall impedance values, to an eigenvalue problem. Acoustic eigenmodes within the duct were computed for several values of the wall acoustic impedance, both with a uniform flow profile and with a sheared flow profile representative of the one obtained in the industrial configuration. Maps of the acoustic attenuation for each cut-on mode were computed, one of which is shown in Fig. 1. The acoustic attenuation was here defined as $A=20 \log \exp \left[\alpha_{i}\right]$, and corresponds then to a decibel loss per meter. Moreover, it was showed that the shape of the flow profile did not change significantly the attenuation map.

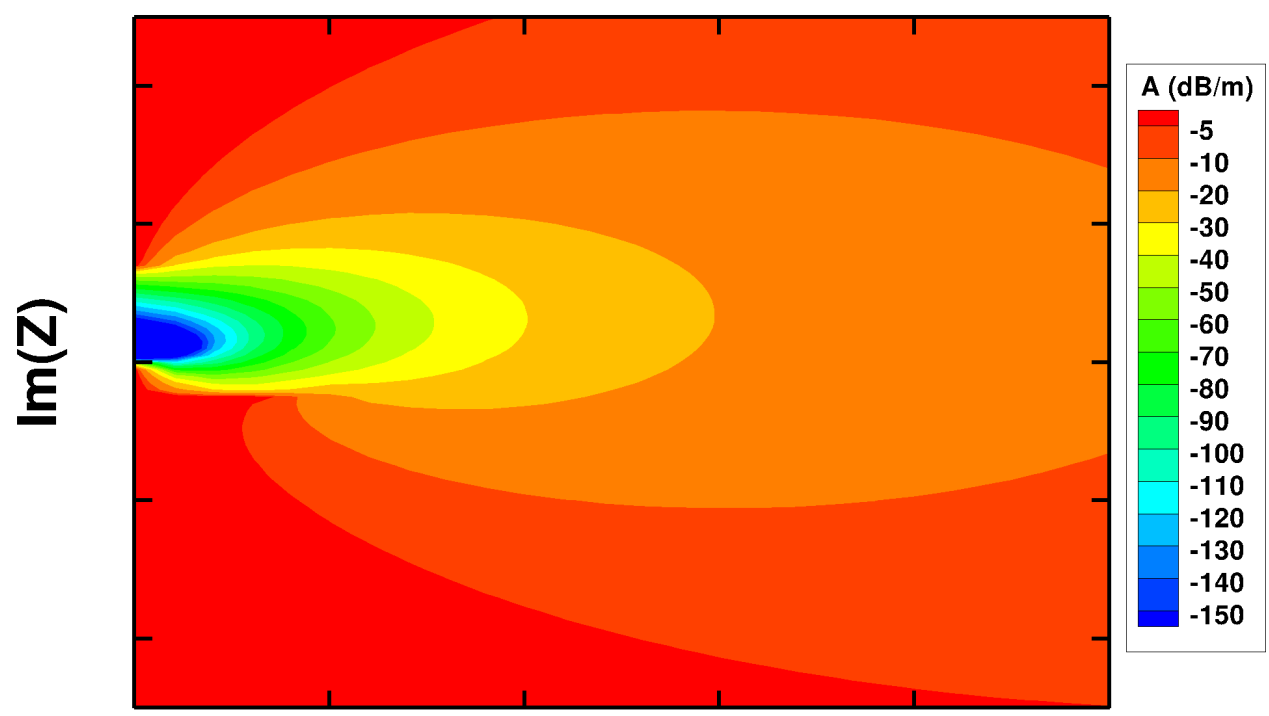

$\operatorname{Re}(Z)$

Figure 1. Attenuation map of a cut-on mode in the impedance plane, obtained with a realistic mean flow profile

Combination of these results allowed the definition of the optimal value of the impedance, i.e. the impedance for which the absorption of the acoustic modes is maximized. However, this optimal value is not always realizable by realistic acoustic treatments, as shown by impedance predictions through semiempirical models. That is why it was preferred to consider a more robust value, that, even if leading to lower attenuation, is more likely to be reached in practice.

Then, the validity of the chosen target impedance was checked by computing the associated acoustic attenuation in the industrial geometry, that is in a geometry made of a truncated cone with cylindrical ducts upstream and downstream. The linearized Euler equations were solved in such a geometry with the ONERA 
in-house code SPACE, based on a Discontinuous Galerkin method. ${ }^{8}$ A sketch of the computational domain is given in Fig. 2.

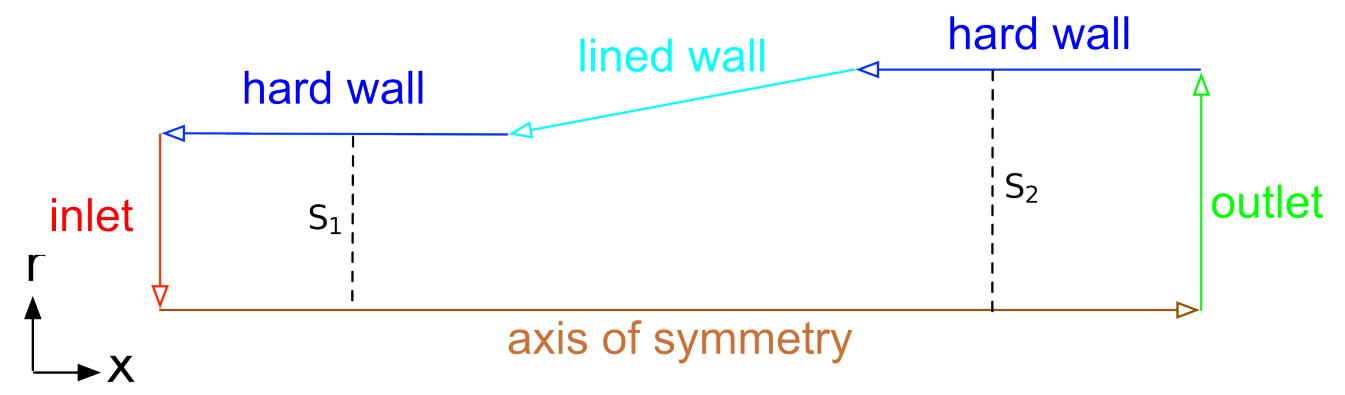

Figure 2. Sketch of the numerical domain. The boundary lined with an acoustic treatment is in cyan.

Computation of the acoustic attenuation between upstream and downstream positions of the treated section allowed the assessment of the acoustic treatment efficiency, for a given frequency, cut-on mode and lined wall impedance value. The attenuation was here defined as :

$$
10 \log \frac{\int_{S_{1}} \mathbf{i} \cdot d \mathbf{S}}{\int_{S_{2}} \mathbf{i} . d \mathbf{S}}
$$

where $S_{1}$ and $S_{2}$ are $(r, \theta)$ planes located upstream and downstream of the lined region, respectively, and where $\mathbf{i}$ denotes the acoustic intensity in the hard duct region, defined by the Cantrell \& Hart expression. ${ }^{9}$ Consequently, this attenuation corresponds to a Transmission Loss through the lined region (with a minus sign).

Computations were done for every cut-on mode at various frequencies and for several values of the impedance around the target one, which provided attenuation maps as displayed in Fig. 3.

These maps confirmed that the chosen frequency evolution of the target impedance allowed significant noise attenuation in the industrial duct. However, as the modal content and modes amplitudes of the noise source were not available, it must be pointed out that the choice of target impedance was made under the assumption that all cut-on modes had the same importance and that interactions between modes could be neglected.

\section{B. Selection of liner concepts}

\section{Design of liners geometrical features}

Next step consisted in finding out liners whose impedance law fitted at best the target impedance in the whole range of frequency. For this, appropriate semi-empirical models from the literature were used. ${ }^{10-12}$ These models link the geometrical features of the liners to their acoustic impedance ${ }^{\mathrm{a}}$, under the assumption of locally-reacting liners. This hypothesis is checked for the Single Degree Of Freedom and Double Degree Of Freedom liners (see Figure 4) considered in the project. The SDOF liners were either classical perforateover-honeycomb liners, or were topped by a wiremesh sheet, to ensure a better linearity versus the mean flow value. The resistive septum of the DDOF liners could either be a perforated or a wiremesh sheet.

Maa's model ${ }^{10}$ was used to predict the impedance of a perforated plate without flow and at low sound pressure level. Especially, it was used for modeling the impedance of DDOF resistive septum when it was made of a perforated plate. The impedance of the perforated plate reads $Z=R+i X$ with :

$$
\begin{aligned}
& R=\frac{32 \nu e}{\sigma c_{0} d^{2}}\left[\left(1+\frac{k_{S}^{2}}{32}\right)^{1 / 2}+\frac{\sqrt{2}}{32} k_{S} \frac{d}{e}\right] \\
& X=\frac{\omega e}{\sigma c_{0}}\left[1+\left(1+\frac{k_{S}^{2}}{2}\right)^{-1 / 2}+\frac{0.85 d}{e}\right]
\end{aligned}
$$

\footnotetext{
${ }^{a}$ throughout this paper only specific acoustic impedance will be given, normalized to $\rho_{0} c_{0}$
} 


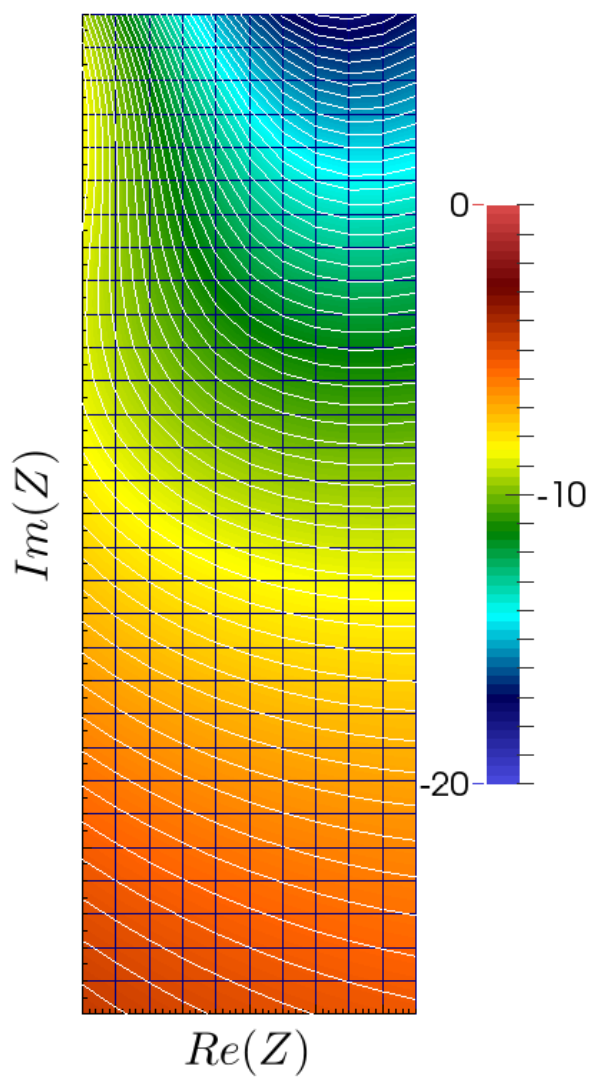

Figure 3. Map in the impedance plane of the acoustic energy reduction along the duct, for a given cut-on mode at a selected frequency. 


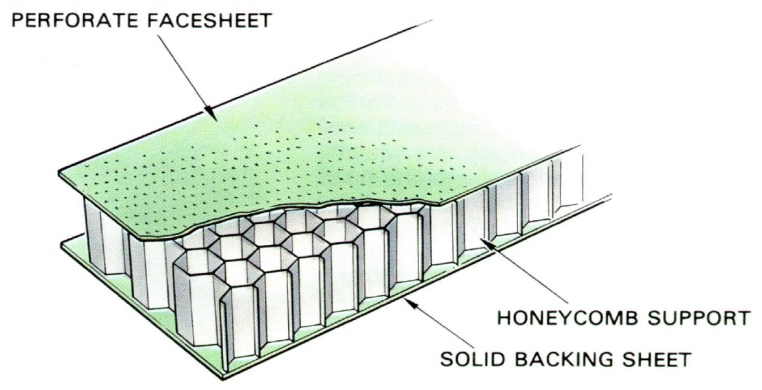

Conventional SDOF

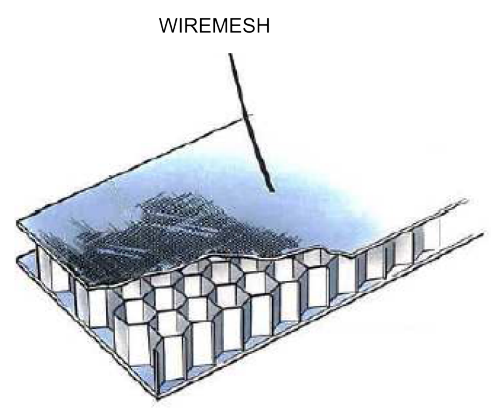

Wiremesh SDOF
PERFORATE FACESHEET

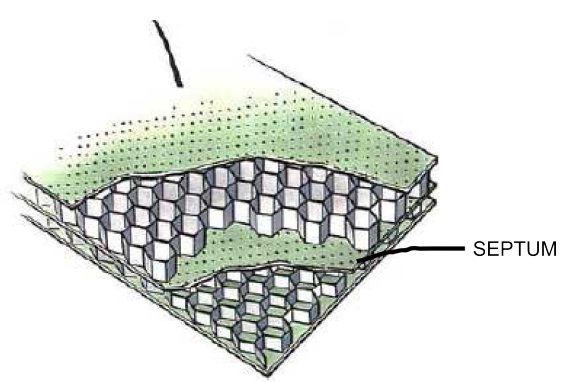

Conventional DDOF

Figure 4. Sketch of SDOF and DDOF liners. 
where $\nu$ is the air kinematic viscosity and

$$
k_{S}=\frac{d}{2} \sqrt{\frac{\omega}{\nu}}
$$

This model was also used for predicting the reactance of the perforated plate topped with a wiremesh sheet, since in this case it was supposed that the liner had become insensitive to the grazing flow. The resistance of such a concept is obtained by dividing the static resistance of the wiremesh sheet by the perforated plate porosity.

On the contrary, Kirby \& Cummings' model ${ }^{12}$ was used for predicting the impedance of a perforated plate submitted to a grazing flow whose friction velocity is denoted as $v^{*}$. The impedance of the perforated plate reads $Z=R+i X$ with :

$$
\begin{gathered}
R=\frac{\sqrt{8 \nu \omega}}{\sigma c_{0}} \frac{e}{d}+\frac{\left[26.16\left(\frac{e}{d}\right)^{-0.169}-20\right] v^{*}}{\sigma c_{0}}-\frac{4.055 f d}{\sigma c_{0}} \\
X=\frac{\omega}{\sigma c_{0}}\left(e+\varepsilon \frac{8 d}{3 \pi}\right)
\end{gathered}
$$

and

$$
\varepsilon=\min \left[1,\left(1+0.6 \frac{e}{d}\right) \exp \left(-\frac{\frac{v^{*}}{f e}-0.18 \frac{d}{e}}{1.8+\frac{e}{d}}\right)-0.6 \frac{e}{d}\right]
$$

An alternative to this model is Kooi \& Sarin's model. ${ }^{11}$ As the previous ones, it stems from a collection of experimental data and the grazing flow effect is taken into account through the friction velocity. It is expected that Kooi \& Sarin's model over-estimates the resistance increase due to grazing flow, while Kirby \& Cummings' model gives an under-estimation. The impedance of the perforated plate reads $Z=R+i X$ with :

$$
\begin{gathered}
R=\frac{\sqrt{8 \nu \omega}}{\sigma c_{0}} \frac{e}{d}+\frac{5-\frac{e}{d}}{\sigma c_{0}}\left(9.9 v^{*}-3.2 f d\right) \\
X=\frac{\omega}{\sigma c_{0}}\left[e+\varepsilon \frac{8 d}{3 \pi}(1-0.7 \sqrt{\sigma})+\left(1+\frac{e}{d}\right) \sqrt{\frac{8 \nu}{\omega}}\right]
\end{gathered}
$$

et

$$
\varepsilon=0.92-0.75 \frac{v^{*}}{f e}+0.11\left(\frac{v^{*}}{f e}\right)^{2}
$$

Finally, impedance of a double-layer liner stems from the impedance of each layer through an expression given for instance in Rienstra's or Eversman's papers. ${ }^{13,14}$ If $Z_{1}$ denotes the impedance of the upper resistive sheet and $Z_{2}$ the impedance of the lower resistive sheet, with $L_{1}$ the upper honeycomb cavity thickness and $L_{2}$ the lower cavity thickness and $L=L_{1}+L_{2}$, then the impedance of the DDOF liner reads :

$$
Z=Z_{1}+\frac{Z_{2} \frac{\cos \left(\omega L_{1} / c_{0}\right) \sin \left(\omega L_{2} / c_{0}\right)}{\sin \left(\omega L / c_{0}\right)}-i \cot \left(\omega L / c_{0}\right)}{1+i Z_{2} \frac{\sin \left(\omega L_{1} / c_{0}\right) \sin \left(\omega L_{2} / c_{0}\right)}{\sin \left(\omega L / c_{0}\right)}}
$$

Based on these models, an optimization procedure was carried out to find the best values of the geometrical parameters so that the liner impedance fits at best to the target impedance. This allowed the selection of five concepts of acoustic treatments. One was a SDOF-like liner (concept $\sharp 1$ ), three were DDOF-like liners (concepts $\sharp 2, \sharp 3$ and $\sharp 4$ ), and the last one was an innovative design dedicated to low-frequency noise attenuation (concept $\sharp 5$ ). All concepts satisfied the tight space restrictions given by Liebherr Aerospace : the liners had to be either one or two inches thick, as summarized in Table 1. Details on concept $\sharp 5$ are not given in the present paper, which focuses on results obtained with conventional liners, but they can be found in dedicated papers by Frank Simon presented in CFA 2016 and INTER-NOISE 2016. ${ }^{15,16}$ 


\begin{tabular}{|c|c|c|c|c|}
\hline Concept $\sharp$ & Kind of treatment & Total thickness & Upper sheet & Inner sheet \\
\hline \hline 1 & SDOF & 1 inch & wiremesh sheet onto a perforated plate & N/A \\
\hline 2 & DDOF & 2 inches & perforated plate & perforated plate \\
\hline 3 & DDOF & 2 inches & perforated plate & wiremesh sheet \\
\hline 4 & DDOF & 1 inch & perforated plate & wiremesh sheet \\
\hline
\end{tabular}

Table 1. Main features of selected conventional concepts

\section{Experimental validation in laboratory facilities}

Laboratory samples of the selected concepts were then manufactured by ATECA for being tested in the ONERA facilities, first in an impedance tube and then in the B2A flow duct (see Fig. 5). The B2A duct is the ONERA aero-thermo-acoustic test bench, in which liner samples can be submitted to a combination of an air flow up to Mach 0.3 and sound pressure levels up to $150 \mathrm{~dB}$. Eight samples were manufactured for ONERA

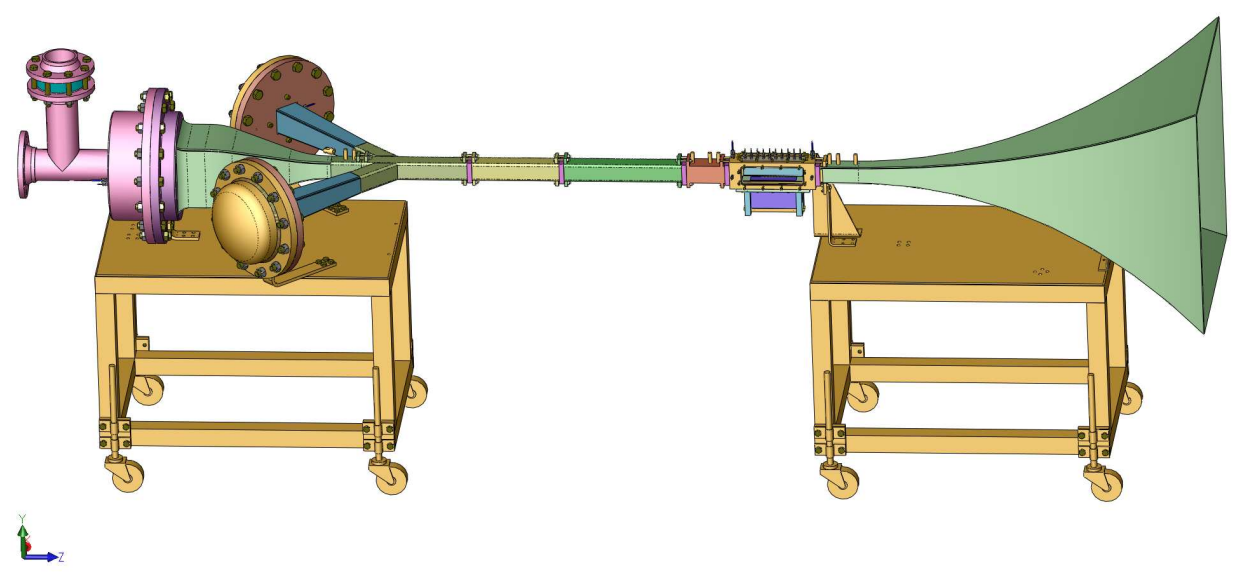

Figure 5. Sketch of B2A Aero-Thermo-Acoustic test bench.

impedance tube : one for each concept, plus an additional design for concept $\sharp 1$ and two additional designs for concept $\sharp 5$. These samples are cylinders of $38 \mathrm{~mm}$ diameter. Moreover, five samples were manufactured for the ONERA flow duct (B2A) : one for each concept. These samples are $150 \mathrm{~mm}$ long and $50 \mathrm{~mm}$ large parallelepipoids.

In the impedance tube, the acoustic impedance without flow was measured, and non-linear effects due to the sound pressure level were assessed. For each liner sample, three levels of the acoustic source were tested: $100 \mathrm{~dB}, 120 \mathrm{~dB}$ and $130 \mathrm{~dB}$. It was found that concept $\sharp 1$ was fully linear with respect to the SPL, as expected. Concepts $\sharp 3$ and $\sharp 4$ were only slightly non-linear with the SPL, while concept $\sharp 2$ resistance showed strong resistance variations when the SPL was increased, which may be problematic for noise reduction in the industrial environment. Impedance results were also compared with the impedance predictions obtained during the concept design phase, which proved the good reliability of the no-flow models.

Then, the sensitivity with respect to grazing flow was assessed during the B2A tests. Acoustic impedance was measured in-situ, without flow and with a grazing flow representative of the industrial setup, both regarding the mean flow velocity and the friction velocity. Of course the shape of the mean flow was 
slightly different from the one obtained in a realistic duct equipped with an air pump, but the preliminary investigation performed with MAMOUT code showed that the acoustic modes attenuation was not very sensitive to this feature. In-situ method is illustrated in Fig. 6, for a DDOF liner. Holes are drilled within the liner so that microphones can be inserted into it. Acoustic pressure is measured at three positions: $p_{1}$ at the upper facesheet, $p_{2}$ at the inner facesheet and $p_{3}$ at the rigid backing of the liner. Then the liner impedance reads :

$$
Z_{\text {in-situ }}=\frac{-i p_{1}}{\sin k L_{1} p_{2}+\cos k L_{1} \sin k L_{2} p_{3}}
$$

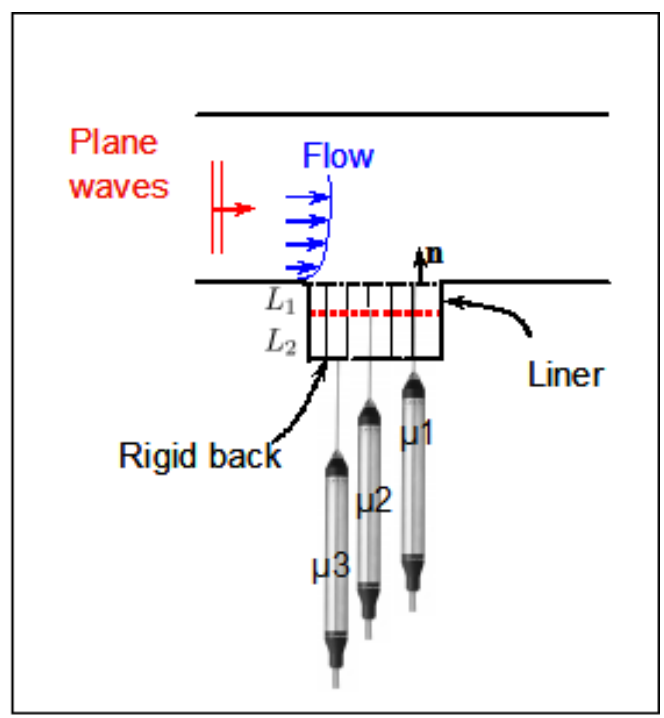

Figure 6. Principle of the in-situ method for impedance measurement: pressure within the liner is measured by a microphone probe located at several positions.

Pressure measurements can be made either in one go, with three phase matched microphones flush mounted to each facesheet, or in three gos, with the same microphone located successively at each position and by keeping each time the same phase reference (for instance another microphone within the flow duct, or the acoustic source). In the present experiments we used the second option, with a $4182 \mathrm{~B} \& \mathrm{~K}$ microphone probe equipped with a $5 \mathrm{~cm}$ long tube, the diameter of which being $1.3 \mathrm{~mm}$.

In-situ results were first checked in the no-flow case by comparison with the impedance tube measurements. In-situ measurements were reliable for every samples except that of concept $\sharp 1$, for which drilling holes had a significant impact on the resistance assessment. However, almost the same resistance was obtained without or with flow, which proved the linearity of this concept with respect to grazing flow. Consequently, impedance tube measurements were considered as being representative of the impedance achieved by liner concept $\sharp 1$.

It must be mentioned that the model-based impedance predictions (see previous section) matched quite correctly the acoustic impedance measurements. As expected, Kooi \& Sarin's model slightly over-estimates the resistance with grazing flow, while Kirby \& Cummings' model under-estimates it.

\section{Numerical assessment of acoustic attenuation in the industrial setup}

Then, for each concept, the measured acoustic impedance values were used as an input for the SPACE code, which predicted the expected noise attenuation in the exact geometry of the industrial settings, as given by Eq. 2. As in the target impedance definition phase, these computations were performed separately for each cut-on mode, which means that any interaction between modes was neglected. An example of result is given in Fig 7.

These numerical predictions allowed the selection of the best two concepts. The selection criteria were not only the reached acoustic attenuation, but also manufacturing, costs and weight considerations. These issues were indeed studied in parallel by ATECA, who performed an analysis for integration of proposed solutions in an industrial context. Finally, the selected designs were concepts $\sharp 1$ and $\sharp 3$, so that both a 1 inch-thick and a 2 inches-thick solutions could be tested. 


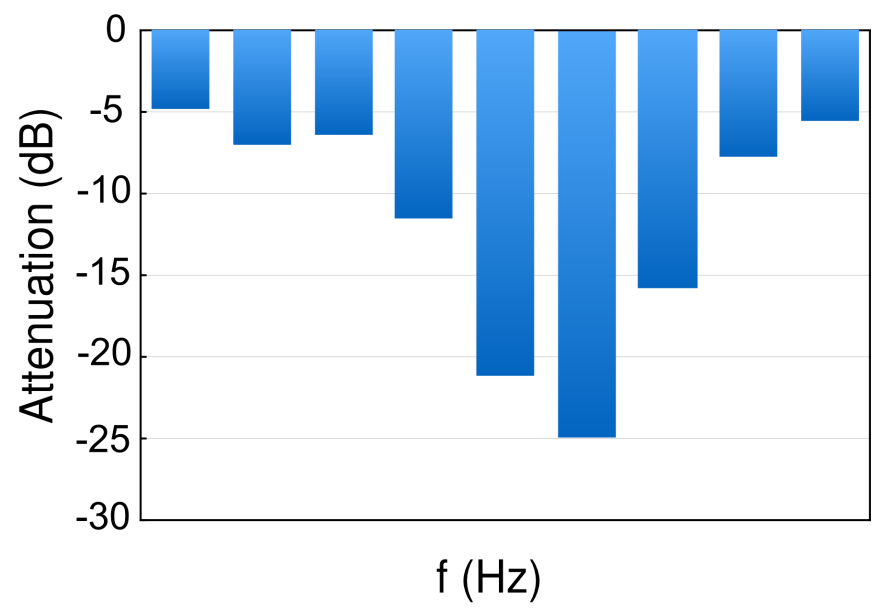

Figure 7. Acoustic attenuation computed in the industrial setup for one of the concepts

\section{Manufacturing and demonstration}

\section{A. Manufacturing of two prototypes}

Large-scale prototypes of the two selected designs were manufactured by ATECA. Pictures of the two coneshaped prototypes can be seen in Fig. 8.

The mass per unit area was calculated for the two solutions : $16.6 \mathrm{~kg} / \mathrm{m}^{2}$ for prototype A and $10.3 \mathrm{~kg} / \mathrm{m}^{2}$ for prototype B.

\section{B. Demonstration in the Liebherr Aerospace acoustic facility}

Both prototypes were tested in industrial settings in the Liebherr Aerospace acoustic facility, and then compared to a baseline configuration (without any acoustic treatment). A sketch of Liebherr Aerospace acoustic facility is displayed in Fig. 9.

The sound power level radiated downstream of the installation, in an anechoic chamber, was measured according to ISO standard 3745_2000, for each configuration and various operating conditions of the jet pump. An example of noise spectrum measured without and with the acoustic treatments is plotted in Figure 10.

The acoustic attenuation provided by the liners prototypes was obtained by comparing the radiated sound power level with that measured without treatment. The attenuation proved to be as high as expected in the target mid-frequency range. This can be illustrated by results plotted in Figure 11, which shows a comparison between the measured and predicted acoustic attenuation, versus frequency.

During the experiments, the operating conditions did not match exactly the mean flow value given in the specifications and used for the numerical simulations. That is why two sets of measurements are plotted in Figure 11 (denoted by PT1 and PT2). The numerical mean flow value is in-between these two operating conditions, which explains why the numerical predictions does not match exactly the measured attenuation. Moreover, in the numerical simulations a Transmission Loss within the duct was computed, while in the experiments an Insertion Loss of the global device was measured. However, it must be mentioned that the difference between TL and IL is reduced if the outlet is anechoic. Despite these small differences on operating conditions and definitions of the acoustic attenuation, the numerical predictions are in very good agreement with the measurements. Especially, the global trends are correctly reproduced.

\section{Conclusions}

During the ALIAS project, ONERA and ATECA combined their research and technological capabilities to design acoustic liners for Liebherr Aerospace jet pump air conditioning system, and manufacture prototypes 


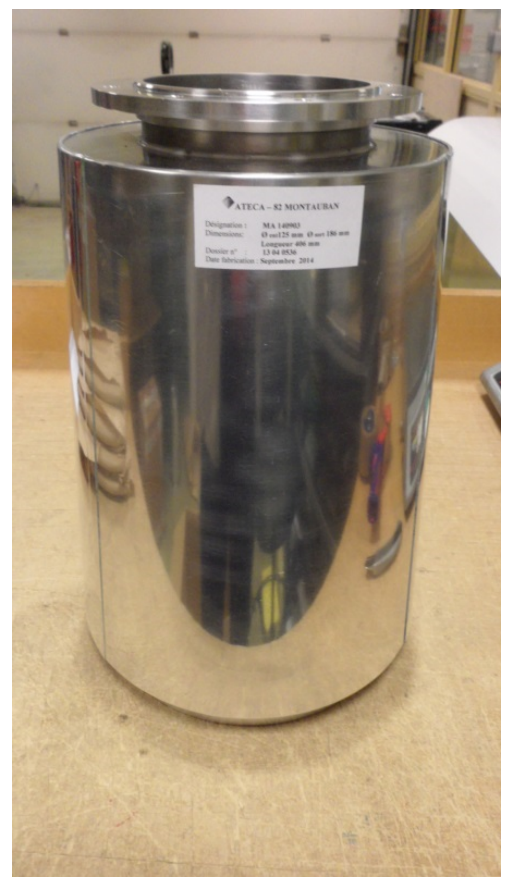

(a) Prototype A i.e. concept $\sharp 3$

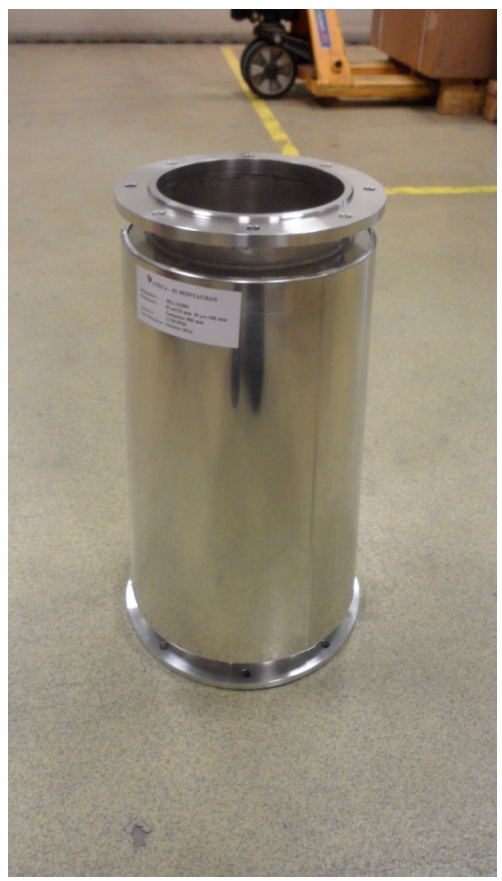

(b) Prototype B i.e. concept $\sharp 1$

Figure 8. Pictures of the two full scale prototypes.

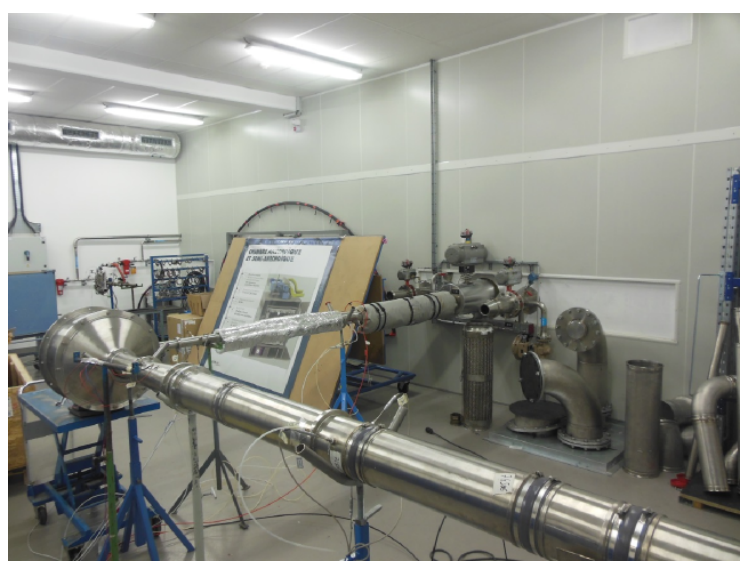

(a) First room with the jet pump box and the downstream duct that can be equipped with the liner prototypes

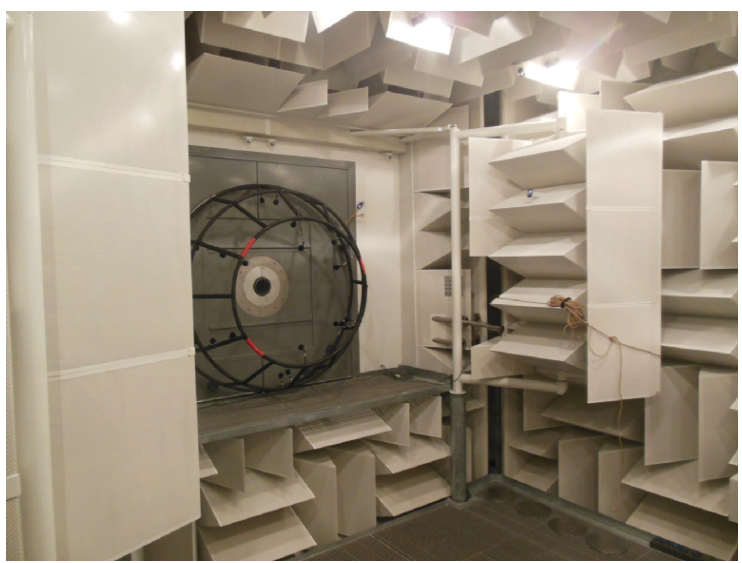

(b) Anechoic chamber downstream of the jet pump room, equipped with a microphone array for noise radiation measurement

Figure 9. Views of Liebherr Aerospace acoustic facility 


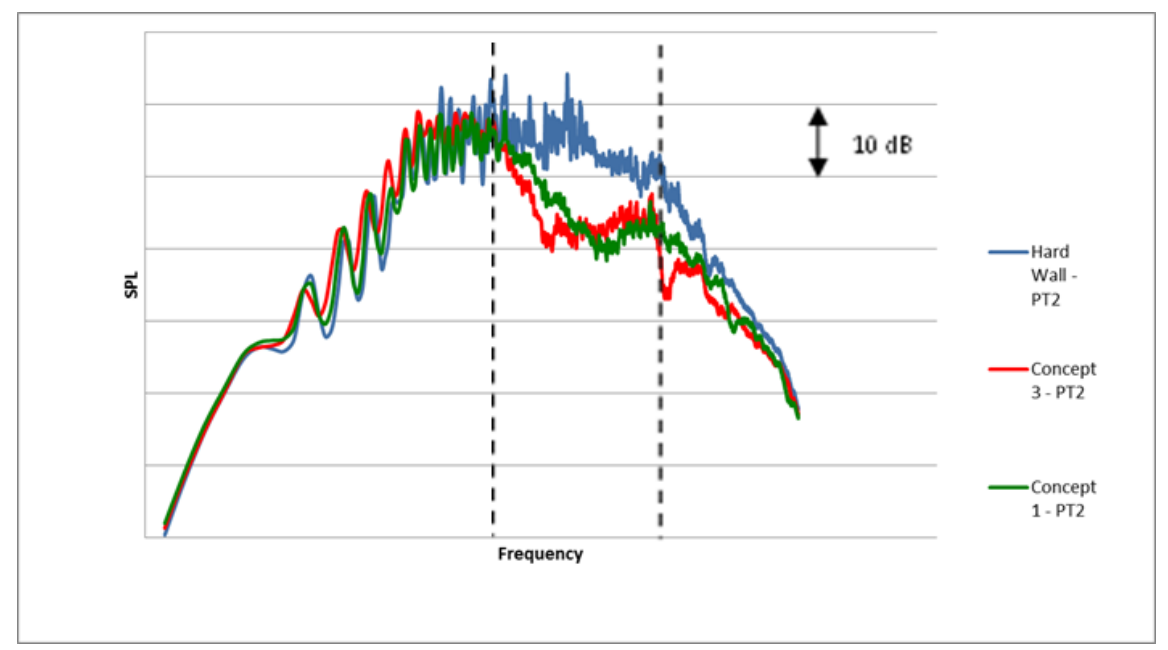

Figure 10. Noise spectrum radiated without treatment (blue line), with Prototype A (red line) and with Prototype B (green line). The target frequency range is displayed by the vertical dashed lines

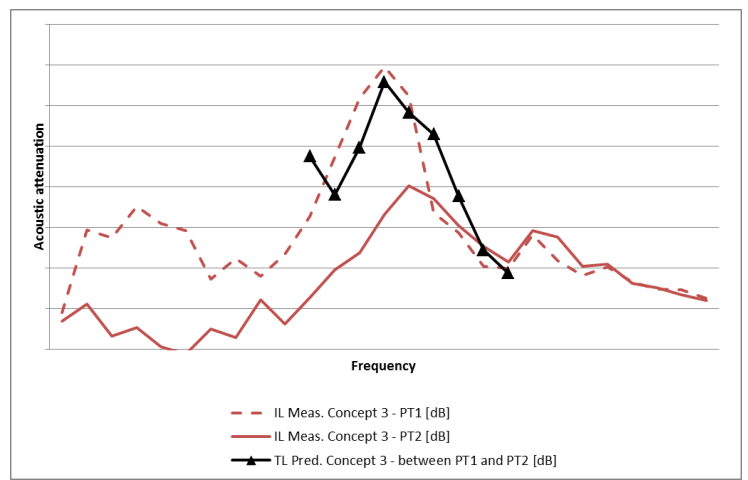

(a) Results with prototype A i.e. concept $\sharp 3$

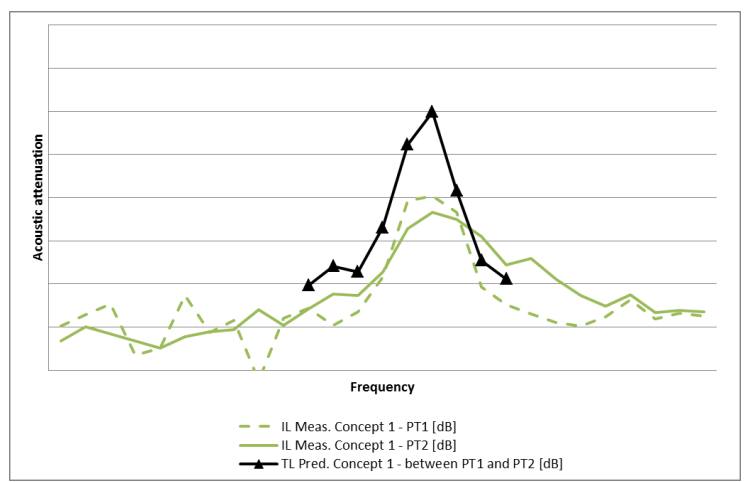

(b) Results with prototype B i.e. concept $\sharp 1$

Figure 11. Comparison between the measured (colored lines) and predicted (black lines with symbols) noise attenuation. 
tested in industrial settings. This work was performed in close cooperation with Liebherr Aerospace, who provided industrial guidelines all along the two-year project and conducted the final tests in its acoustic facility.

Then, ONERA in-house simulation tools (the fast modal analysis code, MAMOUT, as well as a more complex solver of the linearized Euler equations, SPACE) were used to estimate the acoustic liner impedance that maximizes noise damping of the set of cut-on modes in the target range of frequency. A sheared flow profile in a cylindrical duct was considered. The next step was to design locally reacting acoustic liners that best fit the target impedance. For this purpose, semi-empirical models were reproduced from literature to link geometrical properties to the acoustic impedance attained. This allowed the selection of five concepts of acoustic treatments. Laboratory samples of these concepts were then manufactured by ATECA and tested in ONERA facilities, both in an impedance tube and in the B2A flow duct with a grazing flow up to $\mathrm{M}=0.3$. In the flow duct, the acoustic impedance was measured in-situ. The accuracy of theoretical predictions has been confirmed by comparing them with the acoustic impedance measurements. Then, the latter were used as an input for the ONERA acoustic propagation code, which predicted the expected attenuation in the industrial configuration. These numerical predictions allowed the selection of the best two concepts. The selection criteria were not only the reached acoustic attenuation, but also manufacturing, costs and weight considerations. These issues were indeed specifically studied by ATECA, who performed an analysis for integration of proposals solutions in an industrial context. Finally, large-scale prototypes of the two selected designs were manufactured by ATECA and tested in industrial settings in Liebherr Aerospace acoustic facility. The measured acoustic attenuation proved to be as high as expected in the target mid-frequency range, since around $10 \mathrm{~dB}$ of attenuation was achieved. The know-how gained by ALIAS partners could now be used to expand the developed design-based process to various applications in aeronautics, or to other operating conditions of air conditioning systems. Especially, low-frequency noise attenuation under tight thickness restrictions is still an issue to be tackled. One of the innovative design studied during ALIAS project, but not yet manufactured at large-scale, could be a good candidate. Moreover, the liner design process would strongly benefit from the knowledge of the source modal content and noise level within the duct, which remains an open issue.

\section{Acknowledgments}

This work has been undertaken within the Joint Technology Initiative "JTI Clean Sky", Systems for Green Operation Integrated Technology Demonstrator "SGO-ITD", within the ALIAS project (contract No CS-GA-2013-325976) financed by the 7th Framework Program of European Commission.

\section{References}

\footnotetext{
${ }^{1}$ Law, T., Dowling, A., and Corral, R., "Optimisation of axially segmented liners for aeroengine broadband noise," J. Sound Vib., Vol. 329, 2010, pp. 4367-4379.

${ }^{2}$ Mustafi, P., Astley, J., and Sugimoto, R., "A computational study of the effects of liner damage on zero-splice turbofan intake liners," 18th AIAA/CEAS Aeroacoustics Conference (33rd AIAA Aeroacoustics Conference), Colorado Springs, Colorado, USA, June 2012, AIAA-2012-2152.

${ }^{3}$ Tester, B., "The propagation and attenuation of sound in lined ducts containing uniform or "plug" flow," J. Sound Vib., Vol. 28, No. 2, 1973, pp. 151-203.

${ }^{4}$ Motsinger, R. E. and Kraft, R. E., "Design and performance of Duct Acoustic treatment," Aeroacoustics of Flight Vehicles, Theory and Practice, Volume 2, Noise Control, edited by H. H. Hubbard, Acoustical Society of America, 1995, pp. 165-2016.

${ }^{5}$ Malmary, C., Etude Théorique et Expérimentale de L'impédance Acoustique de Matériaux En Présence D'un Ecoulement D'air Tangentiel, Ph.D. thesis, Université du Maine, 2000.

${ }^{6}$ Astley, R., Sugimoto, R., and Mustafi, P., "Computational aero-acoustics for fan duct propagation and radiation. Current status and application to turbofan liner optimisation," J. Sound Vib., Vol. 330, No. 16, 2011, pp. 3832 - 3845.

${ }^{7}$ Boyer, G., Piot, E., and Brazier, J., "Theoretical investigation of hydrodynamic surface mode in a lined duct with sheared flow and comparison with experiment," J. Sound Vib., Vol. 330, 2011, pp. 1793-1809.

${ }^{8}$ Delorme, P., Mazet, P., Peyret, C., and Ventribout, Y., "Computational aeroacoustics applications based on a discontinuous Galerkin method," Comptes Rendus Mécanique, Vol. 333, No. 9, 2005, pp. 676 - 682.

${ }^{9}$ Cantrell, R.-H. and Hart, R.-W., "Interaction between sound and flow in acoustic cavities: mass, momentum and energy considerations," Journal of the Acoustical Society of America, Vol. 36, 1964.

${ }^{10}$ Maa, D. Y., "Potential of microperforated panel absorber," J. Acoust. Soc. Am., Vol. 104, No. 5, 1998, pp. $2861-2866$.

${ }^{11}$ Kooi, J. and Sarin, S., "An experimental study of the acoustic impedance of Helmholtz resonator arrays under a turbulent boundary layer," 7th AIAA Aeroacoustics Conference, AIAA paper 81-1998, Palo Alto, USA, October 1981.
} 
${ }^{12}$ Kirby, R. and Cummings, A., "The impedance of perforated plates subjected to grazing gas flow and backed by porous media," J. Sound Vib., Vol. 217, No. 4, 1998, pp. 619-636.

${ }^{13}$ Rienstra, S., "Impedance Models in Time Domain, including the Extended Helmholtz Resonator Model," 12th AIAA/CEAS Aeroacoustics Conference, 2006, AIAA Paper 2006-2686.

${ }^{14}$ Eversman, W., "Effect of Local Impedance Variation and Non-linearity on Multiple Tone Attenuation," 16th AIAA/CEAS Aeroacoustics Conference, Stockholm, Sweden, June 2010, AIAA Paper 2010-3825.

${ }^{15}$ Simon, F., "Résonateurs acoustiques "basses fréquences" pour application en nacelle moteur avion," 13e Congrès Français d'Acoustique, Le Mans, France, April 11-15 2016.

${ }^{16}$ Simon, F., "Long Elastic Open Neck Acoustic Resonator in flow," 45th International Congress and Exposition on Noise Control Engineering, INTER-NOISE, Hamburg, Germany, August 21-24 2016. 